\title{
Stability Analyses for Seed Yield of Chickpea (Cicer arietinum L.) Genotypes in the Western Cold Zone of Iran
}

\author{
Homayoun Kanouni ${ }^{1}$, Yadolah Farayedi ${ }^{2}$, Ali Saeid ${ }^{3} \&$ Sayyed Hossein Sabaghpour ${ }^{4}$ \\ ${ }^{1}$ Seed and Plant Unit, Agriculture and Natural Resources Research Center of Kurdistan, Sanandaj, Iran \\ ${ }^{2}$ Food Legume Research Department, Dryland Agricultural Research Institute (DARI), Maragheh, Iran \\ ${ }^{3}$ Seed and Plant Unit, Agriculture and Natural Resources Research Center of West-Azerbaijan, Urmia, Iran \\ ${ }^{4}$ Seed and Plant Unit, Agriculture and Natural Resources Research Center of Hamedan, Hamedan, Iran \\ Correspondence: Homayoun Kanouni, Seed and Plant Unit, Agriculture and Natural Resources Research Center \\ of Kurdistan, P. O. Box 714, Sanandaj, Iran. Tel: 98-87-3366-0954. E-mail: hkanouni@yahoo.com
}

\author{
Received: January 12, 2015 Accepted: February 28, 2015 Online Published: April 15, 2015 \\ doi: $10.5539 /$ jas.v7n5p219 \\ URL: http://dx.doi.org/10.5539/jas.v7n5p219
}

\begin{abstract}
Different methods have been developed to estimate of genotype by environment interaction (GEI) in crop plants. In this study, 14 kabuli type chickpea genotypes were assessed for seed yield in four stations over three successive years (2010-2013) at west highlands of Iran. Randomized complete block design was used in all test environments with four replicates. Combined analysis of variance for seed yield revealed significant differences between genotypes, locations, and interaction between these two sources. The mean seed yield of genotypes averaged over environments showed that V4 and V2 had the highest (1163.58 kg ha $\left.{ }^{-1}\right)$ and the lowest seed yield $\left(759.07 \mathrm{~kg} \mathrm{ha}^{-1}\right)$, respectively. Significant GE interaction implied that chickpea genotypes had various responses to different environments and, the stability analysis could be performed. To investigate GEI and identify the best performing stable genotypes, several stability parameters were employed. According to Wricke's ecovalance, stability variance, Plaisted method, and genotypic stability V5, V8 and V3 were the most stable genotypes. Based on $\mathrm{CV}$, regression coefficient and $\mathrm{MS}(\mathrm{GE}), \mathrm{V} 1$ and V5 found to be stable and adapted to diverse environments, and the other genotypes distributed among stability statistics. Based on the AMMI biplot, 12 test environments divided into two mega environments. These mega environments included very cold districts like Maragheh and similar areas, and relatively softened regions of Kurdistan and similar environments. For these two mega environments, V6 and V4 showed more adaptability, respectively. In conclusion, the two genotypes, V4 (FLIP 00-39C) and V6 (FLIP 99-26C) could be recommended as new cultivars to chickpea farmers for autumn sowing in west areas of Iran.
\end{abstract}

Keywords: chickpea, $\mathrm{G} \times \mathrm{E}$ interaction, stability parameters, seed yield

\section{Introduction}

Chickpea is one of the most important components of agricultural systems in Iran (Kanouni et al., 2006). Iran ranks seventh in chickpea growth and production after India, Australia, Turkey, Myanmar, Pakistan and Ethiopia (FAOSATA, 2012). Chickpea (Cicer arietinum L.), which is the unique agronomic species in genus Cicer, provides a non-expensive and high quality protein rich source for poor societies. Chickpea has two Desi and Kabuli types, which are sowing in different parts of the world, and one has preference over another based on consumer's taste. During 2011-12, production and the area under sowing of chickpea in Iran were 300 thousand tone and 550 thousand ha, respectively (Danyali et al., 2012). Average seed yield of chickpea in Iran is $350 \mathrm{~kg}$ $\mathrm{ha}^{-1}$, which is lower than world's average. Whereas, potential yield of $4000 \mathrm{~kg} \mathrm{ha}^{-1}$ has been recorded in a farm in Syria (Singh \& Saxena, 1999). This gap between average and potential yield of chickpea could be due to susceptibility of this crop to the abiotic constraints.

In a field trial, a genotype may be known as superior variety when have high potential to produce seed yield at different environmental conditions, as well as high level of phenotypic stability, simultaneously. When GEI has importance to plant breeders, stability and adaptability parameters of yield will help them to find superior varieties and adaptation of these varieties to a divers set of environmental conditions. However, breeding for yield increment has highly depending on selection of favorable genotypes to the target environment (Bakhsh et 
al., 2009; Raffi et al., 2004).

From three components of phenotypic variation (Genotype, environment and genotype by environment interaction), so far the highest attention allocated to genotype (Halluer \& Miranda, 1981). Between other two components, environment and GEI, during last decades GEI has investigated more (Lin et al., 1986). In this regard, different regression models have been applied widely, and several univariate and multivariate parametric and non-parametric statistics have been suggested to identifying response of genotypes to the environmental variations.

Phenotypic stability has been studied widely by biometricians, who have developed several methods for its analysis (Eberhart \& Rusell, 1966; Lin \& Binns, 1988). Lin et al. (1986) have classified stability parameters in three groups namely type I, II and III. By type I, a genotype has named stable when its environmental variance is small. Environmental variance $\mathrm{S}_{\mathrm{i}}{ }^{2}$ (Romer, 1917; cited from Becker \& Léon, 1988), regression coefficient (Finley \& Wilkinson, 1963), and coefficient of variation (Francies \& Kanenberg, 1978) are belonging to this group. In type II, which stability of Shukla (Shukla, 1972), Wricke's ecovalance (Wricke, 1965), variance mean of Plaisted and Peterson (1959), Plaisted (1960) variance, and regression coefficient of Finlay and Wilkinson (1963) classified in this group, a genotype is stable when its response to environment is parallel with average response of all experimental genotypes. In the stability type III, which includes squared deviations from the regression (Eberhart \& Russell, 1966) and coefficient of determination (Pinthus, 1976), a genotype considers stable when mean of residual squares is smaller than regression models on environmental index. Later Lin and Binns (1988) proposed a fourth type. In type IV, a variety considers to be stable if the year mean square in locations is small. Wricke (1962) suggested that contribution of a genotype in interaction's sum of square could be used as an estimate of stability $\left(w_{i}\right)$. Shukla (1972), to obtain an unbiased estimate of GEI variance for each genotype, made changes in ecovalance $\left(w_{i}\right)$ and called it stability variance. Francis and Kannenberg (1978) used coefficient of variation of each genotype as an estimate of stability. Lin and Binns have developed a priority index $\left(\mathrm{P}_{\mathrm{i}}\right)$ or superiority measure of genotypic performance, which defined as the distance mean square between the cultivar's response and the maximum response averaged over all locations. Kang (1988) suggested a rank-sum method that provides selection for yield and the stability variance statistic, simultaneously. Rank-sum obtains via summation rank of mean yield and rank of Shukla's stability variance. However, lower rank-sum indicates greater stability. Based on Tai's stability parameters (Tai, 1971), a perfectly stable cultivar has $\lambda=1$ and $\alpha=-1$. Average stability can identify by $(\alpha, \lambda)=(1,0)$. In higher and lower than average, $\alpha$ is smaller and larger than zero, respectively.

Multivariate stability statistics have been proposed to eliminate noise from the data, and to reveal the structure in the data (Akter et al., 2014; Zobel et al., 1982). One of the most applicable multivariate parameters, which have a high scientific validity, is additive main effects and multiplicative interactions (AMMI) method. AMMI model increases the probability of high yielding genotypes selection (Zobel et al., 1982). Furthermore, this model has integrated analysis of variance (ANOVA) and principal component analysis (PCA) which applies to estimate the main effect of genotypes as well as genotypic and environmental components of interaction, respectively. However, the AMMI model does not make provision for a quantitative stability measure, such a measure is provided by AMMI stability values (ASV) which quantify and rank genotypes according to their yield stability (Purchase et al., 2000).

There is little information on the yield stability of chickpea in Iran. Hence, the objectives of this study were: (1) to identify high and stable yielding chickpea genotypes across environmental variation and (2) to study the measure of genotype $\times$ environment interaction in chickpea genotypes.

\section{Material and Methods}

Data analyzed in this study obtained via a set of yield trials conducted during three consecutive years, 2010 to 20 13, at four experimental stations of west of Iran including Kurdistan, Maragheh, Urmia and Hamedan. More details about these locations has presented in Table1. At each environments (year by location integration), 13 elite chickpea genotypes which were developed by International Center for Agricultural Research in the Dry Areas (ICARDA), as well as one local check, Djam (Table 2), studied in randomized complete block design (RCBD) with four replicates. The experiments were conducted on $1^{\text {st }}$ week of October and plant population density was maintained with 35 plants per $\mathrm{m}^{2}$ in all locations. 
Table 1. Code and climatic properties of experimental environments, west of Iran (2010-13)

\begin{tabular}{|c|c|c|c|c|c|c|c|c|}
\hline \multicolumn{4}{|c|}{ Environments } & \multirow{2}{*}{ Latitude \& Longitude } & \multirow{2}{*}{ Altitude (m) } & \multicolumn{2}{|c|}{ Temp. $\left({ }^{\circ} \mathrm{C}\right)$} & \multirow{2}{*}{ Annual Rainfall (mm } \\
\hline Location & Year & Code & Env. Index & & & Min. & Max. & \\
\hline \multirow[t]{3}{*}{ Maragheh } & $2010-11$ & M1 & 727.48 & $37^{\circ} 24^{\prime} \mathrm{N}$ & 1720 & -15.28 & 36.25 & 498.10 \\
\hline & 2011-12 & M2 & -181.82 & $47^{\circ} 15^{\prime} \mathrm{E}$ & & -18.11 & 34.52 & 351.40 \\
\hline & $2012-13$ & M3 & 14.33 & & & -21.53 & 35.77 & 263.20 \\
\hline \multirow[t]{3}{*}{ Kurdistan } & $2010-11$ & $\mathrm{~K} 1$ & 393.86 & $35^{\circ} 40^{\prime} \mathrm{N}$ & 2120 & -16.05 & 36.66 & 442.30 \\
\hline & 2011-12 & K2 & -102.07 & $47^{\circ} 07^{\prime} \mathrm{E}$ & & -20.41 & 30.18 & 305.11 \\
\hline & $2012-13$ & K3 & -615.80 & & & -18.22 & 32.80 & 352.80 \\
\hline \multirow[t]{3}{*}{ Urmia } & $2010-11$ & U1 & 925.12 & $37^{\circ} 32^{\prime} \mathrm{N}$ & 1880 & -17.22 & 33.23 & 291.22 \\
\hline & 2011-12 & $\mathrm{U} 2$ & -12.47 & $45^{\circ} 5^{\prime} \mathrm{E}$ & & -17.93 & 29.61 & 303.20 \\
\hline & $2012-13$ & U3 & -327.84 & & & -19.32 & 30.44 & 300.16 \\
\hline \multirow[t]{3}{*}{ Hamedan } & 2010-11 & H1 & 55.20 & $37^{\circ} 32^{\prime} \mathrm{N}$ & 1610 & -15.64 & 32.09 & 298.93 \\
\hline & 2011-12 & $\mathrm{H} 2$ & -627.08 & $45^{\circ} 5^{\prime} \mathrm{E}$ & & -16.19 & 31.38 & 309.37 \\
\hline & 2012-13 & $\mathrm{H} 3$ & -248.91 & & & -14.24 & 31.44 & 333.05 \\
\hline
\end{tabular}

Table 2. Name, origin, and code of chickpea genotypes used in the experiment

\begin{tabular}{|c|c|c|c|c|c|}
\hline Genotype Name & Origin & Code & Genotype Name & Origin & Code \\
\hline FLIP 01-40C & ICARDA & $\mathrm{V} 1$ & FLIP 02-512C & ICARDA & V8 \\
\hline SEL 99 TH150454 & ICARDA & V2 & FLIP 00-84C & ICARDA & V9 \\
\hline FLIP 97-85C & ICARDA & V3 & FLIP 01-9C & ICARDA & V10 \\
\hline FLIP 00-39C & ICARDA & V4 & FLIP 01-18C & ICARDA & V11 \\
\hline FLIP 97-230C & ICARDA & V5 & FLIP 98-15C & ICARDA & V12 \\
\hline FLIP 99-26C & ICARDA & V6 & FLIP 99-45C & ICARDA & V13 \\
\hline FLIP 02-84 & ICARDA & V7 & DJAM (Check) & Iran & V14 \\
\hline
\end{tabular}

For each location every year, analysis of variance was performed. At the next step, Bartlett's homogeneity test of variances was accomplished. Subsequently, referring to result of Bartlett's test, combined analysis of variance was done (Crossa, 1990). Stability statistics including coefficient of variation (Franscis \& Kannenberg, 1978), Wricke's ecovalance (Wricke, 1962), Shukla stability variance (Shukla, 1972), regression line slop (Finlay \& Wilkinson, 1963), genotypic stability (Hanson, 1970), Plaisted stability parameter (1960), mean square of GEI (Lin \& Binns, 1988), priority index (Lin \& Binns, 1988), and Tai’s alpha and lambda (1971) were performed for each genotype. Rank-sum method (Kang, 1988), as one non-parametric statistic was measured for experimental genotypes. Among multivariate stability parameters, AMMI model was used to investigate of GE interaction and could be indicated as below (Thillainathan \& Fernandez, 2001):

$$
Y_{g e}=\mu+\alpha_{g}+\beta_{e}+\sum_{n=1}^{N} \lambda_{n} \gamma_{g n}^{2} \delta_{e n}+\theta_{g e}
$$

Where,

$Y_{g e}$ isyield of genotype by environment, $\mu$ is grand mean, $\alpha_{g}$ is genotype mean deviations, $\beta_{e}$ is environmental mean deviations, $\lambda_{n}$ is eigen value of PCA axis $\mathrm{n}, \gamma_{g n}^{2}$ and $\delta_{e n}$ are genotype and environment PCA scores for PCA axis $\mathrm{n}, \mathrm{N}$ is number of PCA axes retained in the model and $\theta_{g e}$ is residuals.

To employ of AMMI stability value (ASV), the following equation was proposed by Purchase et al. (2000):

$$
\text { AMMI Stability Value (ASV) }=\sqrt{\frac{I P C 1 \text { sum of squares }}{I P C 2 \text { sum of squares }} I P C 1^{2}+I P C 2^{2}}
$$

The ASV is the distance from zero in a two dimensional plot of IPCA1 (Interaction Principal Component Analysis axis 1) scores against IPCA2 scores. Since the IPCA1 score contributes more to $G \times E$ sum of squares, 
it has to be weighted by the proportional difference between IPCA1 and IPCA2 scores to compensate for the relative contribution of IPCA1 and IPCA2 total $\mathrm{G} \times \mathrm{E}$ sum of squares.

A detailed explanation on mathematical basis of AMMI analysis and its interpretations has been presented by Hussein et al. (2000). All analyzes performed using SAS GLM procedures (SAS Institute, 1999).

\section{Results and Discussion}

\subsection{Analysis of Variance}

Prior to combined analysis of variance, homogeneity of error variances of twelve experiments was determined by Bartlett's test. Result of this test revealed that environments were not heterogeneous. However, combined analysis of variance of environment, genotype, and GE interaction were significant for seed yield (Table 3). Significant GE interaction implied that chickpea genotypes had various responses to different environments and, the stability analysis could be performed to estimate the adaptation of the genotypes. More than $70 \%$ of the total sum of square explained by environment, whereas, only $3 \%$ of variation attributed to genotypes and $11 \%$ of that variation explained via GE interaction. Gauch and Zobel (1988) believe that, low variance of genotypic effect may be due to proximity of genetic potential of the test genotypes.

Table 3. Combined ANOVA of seed yield for 14 chickpea genotypes at 12 environments of Iran (2010-13)

\begin{tabular}{llllll}
\hline S.O.V. & d.f. & SS & MS & F & Explained\% \\
\hline Environment (E) & 11 & 141509118 & 12864465 & $102.21^{* *}$ & 70.61 \\
Replication/E & 36 & 4530979 & 125861 & $2.31^{* *}$ & 2.26 \\
Genotype(G) & 13 & 6423185 & 494091 & $3.14^{* *}$ & 3.20 \\
G $\times$ E & 143 & 22473269 & 157156 & $2.89^{* *}$ & 11.21 \\
Error & 468 & 25477431 & 54439 & & 12.71 \\
\hline Total & 671 & 200413982 & & & \\
CV\% & & 23.16 & & &
\end{tabular}

Note. S.O.V. $=$ source of variation; d.f. $=$ degree of freedom; $\mathrm{SS}=$ sum of square; MS = mean square; $* *=$ Significant at $1 \%$ probability level.

Mean seed yield of chickpea genotypes varied between $1163.5 \mathrm{~kg} \mathrm{ha}^{-1}$ for V4 and $756.02 \mathrm{~kg} \mathrm{ha}^{-1}$ for V2 (Table 5). Grand mean of seed yield over 12 locations and mean yield of check variety (Djam) were 1007.26 and $968.91 \mathrm{~kg}$ $\mathrm{ha}^{-1}$, respectively. The least significant difference (LSD) value for means comparison was $189.87 \mathrm{~kg} \mathrm{ha}^{-1}$. The LSD value shows that there were significant differences among genotypes $(\mathrm{P} \leq 0.05)$.

\subsection{Stability Analysis}

Regression of location on seed yield for 14 chickpea genotypes across different location and year combinations analyzed and results have shown in Table 4. These results imply that, genotype by environment interaction (linear) is significant $(\mathrm{P}<0.05)$. This significant effect identified linear relationship between yield of genotypes and environmental index. In other words, the slope of the regression line for test genotypes is not same for all. 
Table 4. Stability analysis for seed yield of chickpea genotypes with regression of location on yield in Iran (2010-13)

\begin{tabular}{|c|c|c|c|c|c|}
\hline S.O.V. & d.f. & SS & MS & $\mathrm{F}$ & $\mathrm{P}$ value \\
\hline Genotype (G) & 13 & $0.1605 \mathrm{E}+07$ & 123523.1 & & \\
\hline Environment (E) & 11 & $0.353773 \mathrm{E}+07$ & $0.321612 \mathrm{E}+07$ & & \\
\hline Regression & 1 & $0.141509 \mathrm{E}+09$ & $0.141509 \mathrm{E}+09$ & & \\
\hline Deviation & 10 & $-0.106132 \mathrm{E}+09$ & $-0.106132 \mathrm{E}+08$ & & \\
\hline $\mathrm{G} \times \mathrm{E}$ & 143 & $0.561832 \mathrm{E}+07$ & 39288.9 & & \\
\hline $\mathrm{G} \times \mathrm{E}$ (Linear) & 13 & $0.1032 \mathrm{E}+07$ & 79454.3 & 2.253 & 0.011 \\
\hline Deviation & 130 & $0.4585 \mathrm{E}+07$ & 35272.4 & & \\
\hline Total & 167 & $1.07611+07$ & & & \\
\hline
\end{tabular}

The genotypes with significantly higher ecovalance $\left(\mathrm{W}_{\mathrm{i}}\right)(\mathrm{P}<0.05)$ are presented in Table 5 . Corresponding to Wrick's ecovalance $\left(\mathrm{W}_{\mathrm{i}}\right)$, genotypes of $\mathrm{V} 5, \mathrm{~V} 8$, and $\mathrm{V} 3$ had less ecovalance than others, respectively and considered more stable genotypes across environments. Based on Plaisted method $\left(\theta_{(\mathrm{i})}\right)$, genotypes V5, V8, and V3 estimated higher value of $\theta_{(\mathrm{i})}$ and were considered more stable than others. Regression coefficient $\left(\mathrm{b}_{\mathrm{i}}\right)$ of varieties on the environmental index, ranged from 0.597 to 1.333 . According to this parameter (Fransis \& Kanenberg, 1978), genotypes with line slop close to one have general adaptability. Regards to this parameter, all genotypes in this study, unless V2, V6 and V11 were not significant. In fact, these genotypes have potential to increase their seed yield with improvement of environmental conditions. According to the of coefficient of variation proposed by Fransis and Kanenberg (CV), genotypes V9 and V12 with less CV and high seed yield seems to be more stable. In line with Lin and Binns statistics $\left(\mathrm{P}_{\mathrm{i}}\right)$ and MS(GE), it could be seen that, V4, V6, and V9 have less $P_{i}$ values and are considered relatively stable . Though, based on MS(GE), genotypes V1, V5, and V7 were stable. Lin \& Binns (1988) tested both Pi and MS(GE) against the MS of deviation from regression. Based on stability variance $\left(\sigma_{\mathrm{i}}^{2}\right)$ of Shukla (1972), residual variance for each genotype was calculated and explored that, genotypes of V5, V8, and V3 had less variance. Becker and Léon (1988) suggested that ecovalance (Wricke, 1962) and stability variance (Shukla, 1972) give same results for ranking of genotypes. Hanson (1970) has proposed a genotypic stability $\left(\mathrm{D}_{\mathrm{i}}{ }^{2}\right)$, which based on this statistic genotypes V3, V5, and V1 were most stable. Considering regression procedure of Tai (1971), the highest stability was obtained by genotypes V6, V9 and V12 (Figure 1). As shown in Figure 1, a three-dimension plot presents the genotypes that have alpha and lambda amounts closer to -1 and 1, respectively. Based on this procedure, V3 and V5 could be selected as stable genotypes. Non-parametric statistic of rank-sum (Kang, 1988) showed that V1, V5, and V8 had desirable stability. All these genotypes had lower performance than grand mean. Using this parameter, V2 with lowest seed yield identified as the most non-stable genotype.

It is common that, it will be difficult to find a unique strategy for evaluating the stability of all varieties across all environments. Some of scientists believe that, should use all stability analysis methods including parametric and non-parametric, univariate and multivariate methods and then take a general conclusion (Kang, 1988; Yan \& Kang, 2003). 
Table 5. Genotypic mean $\left(\mathrm{kg} \mathrm{ha}^{-1}\right)$ and stability parameters for 14 kabuli type chickpea genotypes across different environments in Iran (2010-13).

\begin{tabular}{|c|c|c|c|c|c|c|c|c|c|c|c|c|}
\hline \multirow{2}{*}{ Code } & \multirow{2}{*}{$\begin{array}{l}\text { Mean } \\
\left(\mathrm{kg} \mathrm{ha}^{-1}\right)\end{array}$} & \multicolumn{11}{|c|}{ Parameters } \\
\hline & & $\mathrm{W}_{\mathrm{i}}$ & $\theta_{(\mathrm{i})}$ & $b_{i}$ & $\mathrm{CV}$ & $P_{i}$ & $\mathrm{MS}(\mathrm{GE})$ & $\sigma_{i}^{2}$ & $\mathrm{D}_{\mathrm{i}}^{2}$ & $\alpha_{\mathrm{i}}$ & $\lambda_{\mathrm{i}}$ & RS \\
\hline $\mathrm{V}_{1}$ & 982.33 & 284709.31 & 40163.10 & 0.951 & 48.95 & $101460.55^{*}$ & 20961.10 & 26928.30 & 589338.37 & -0.0540 & 1.996 & 14 \\
\hline $\mathrm{V}_{2}$ & 756.02 & $1128033.57^{*}$ & 33282.84 & $0.597^{*}$ & 50.61 & $291019.47^{*}$ & $94103.30^{*}$ & $116371.78^{*}$ & 713999.62 & $-0.4089 *$ & $5.104 *$ & 28 \\
\hline $\mathrm{V}_{3}$ & 945.08 & 177507.76 & 41037.71 & 0.859 & 44.96 & 136411.93* & 40273.82 & 15558.43 & 299529.88 & $-0.1442^{*}$ & 0.903 & 16 \\
\hline $\mathrm{V}_{4}$ & 1163.5 & $625514.91 *$ & 37382.64 & 1.159 & 51.34 & 47658.47 & 23448.75 & $63074.34 *$ & 1351139.10 & 0.1539 & $4.073 *$ & 14 \\
\hline $\mathrm{V}_{5}$ & 983.07 & 87201.27 & 41774.47 & 1.022 & 50.52 & $98735.12 *$ & 18534.17 & 5980.47 & 540664.00 & 0.0195 & 0.620 & 9 \\
\hline $\mathrm{V}_{6}$ & 1141.2 & 522411.01* & 38223.81 & $1.333 *$ & 57.52 & 52500.67 & 23128.21 & $52139.08^{*}$ & 1619695.82 & $0.3374^{*}$ & 1.708 & 13 \\
\hline $\mathrm{V}_{7}$ & 1015.7 & 274090.68 & 40249.74 & 0.958 & 47.66 & $90677.39 *$ & 23001.65 & 25802.08 & 597114.59 & -0.0449 & $1.935^{*}$ & 10 \\
\hline $\mathrm{V}_{8}$ & 974.21 & 175058.83 & 41057.69 & 1.038 & 52.89 & $109313.69 *$ & 25524.78 & 15298.70 & 676486.33 & 0.0432 & 1.225 & 12 \\
\hline $\mathrm{V}_{9}$ & 1111.3 & $405369.20^{*}$ & 39178.70 & 0.956 & 44.62 & 72583.56 & 35512.70 & $39725.56^{*}$ & 726464.29 & -0.0459 & $2.878^{*}$ & 13 \\
\hline $\mathrm{V}_{10}$ & 994.64 & $333955.32 *$ & 39761.33 & 0.987 & 50.57 & $110661.15^{*}$ & 35023.99 & $32151.36^{*}$ & 715657.05 & -0.0159 & $2.397 *$ & 14 \\
\hline $\mathrm{V}_{11}$ & 1069.5 & $523688.95^{*}$ & 38213.39 & $1.255^{*}$ & 59.39 & 80867.64 & 31533.59 & $52274.62^{*}$ & 1498139.25 & 0.2768 & $2.388^{*}$ & 16 \\
\hline $\mathrm{V}_{12}$ & 1051.0 & $370263.02 *$ & 39465.11 & 0.937 & 45.96 & 80549.32 & 25254.70 & $36002.17 *$ & 649905.87 & -0.0664 & $2.584^{*}$ & 13 \\
\hline $\mathrm{V}_{13}$ & 945.14 & 300070.18 & 40037.78 & 0.963 & 51.77 & $132808.17^{*}$ & 36693.26 & 28557.48 & 634974.11 & -0.0391 & $2.131 *$ & 18 \\
\hline $\mathrm{V}_{14}$ & 968.91 & $400265.65^{*}$ & 39220.34 & 0.985 & 52.57 & $156555.22 *$ & 48621.98 & $39184.27 *$ & 792029.92 & -0.0083 & $2.878^{*}$ & 20 \\
\hline
\end{tabular}

Note. ${ }^{*}$ Significant at $5 \%$ probability level; LSD $5 \%=189.87 \mathrm{~kg} \mathrm{ha}^{-1} ;$ Mean $=$ Mean yield; Wi $=$ Wricke's ecovalance, $\theta_{(\mathrm{i})}=$ Plaisted's stability parameter; bi = coefficient of regression; $\mathrm{CV}=$ coefficient of variation; $\mathrm{Pi}=$ priority index, $\mathrm{MS}(\mathrm{GE})=$ mean squares of genotype by environment interactions; $\sigma_{\mathrm{i}}{ }^{2}=$ stability variance; $\mathrm{D}_{\mathrm{i}}{ }^{2}=$ genotypic stability, $\alpha_{\mathrm{i}} \& \lambda_{\mathrm{i}}=$ Tai's alpha and Lambda, RS = rank-sum.

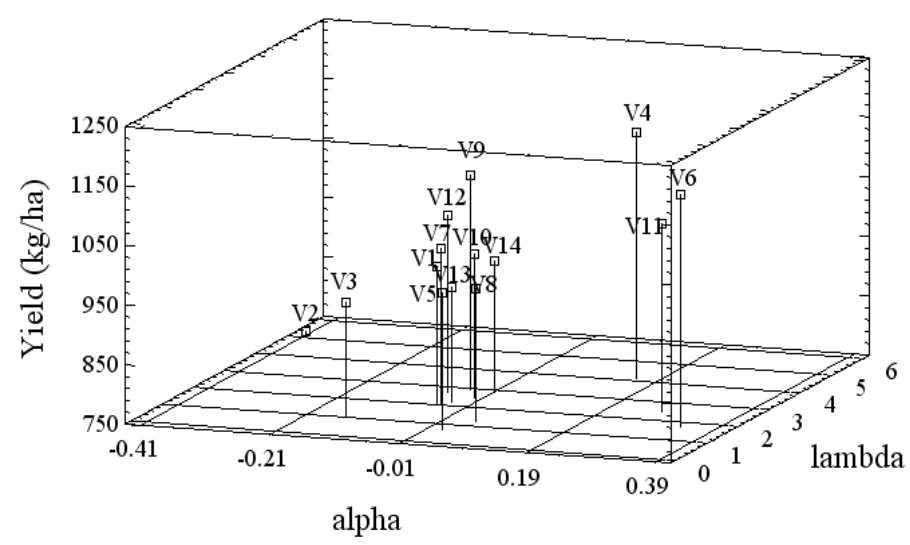

Figure 1. Scatter (3-D) plot of Tai's alpha and lambda statistics versus mean seed yield of 14 chickpea genotypes

Analysis of additive main effects and multiplicative interactions (AMMI) for seed yield of 14 elite chickpea genotypes at 12 environments are presented in Table 6 . As can be seen, $82.2 \%$ of the total sum of squares is attributed to the environmental effects, and only $4.6 \%$ has allocated to genotype and $13.2 \%$ to genotype by environment interaction. Large amount of environment SS imply that experimental environments are varied, and great differences between mean of environments has created main portion of variations in seed yield of experimental genotypes. 
Table 6. AMMI analysis for seed yield of 14 chickpea genotypes at 12 environments of Iran

\begin{tabular}{|c|c|c|c|c|c|c|}
\hline S.O.V. & d.f. & $\mathrm{SS}$ & MS & $\mathrm{F}$ & Prob. level & Explained\% \\
\hline Genotype (G) & 13 & $0.160 \mathrm{E}+07$ & 123523.1 & & & 4.6 \\
\hline Environment (E) & 11 & $0.353 \mathrm{E}+07$ & $0.321 \mathrm{E}+07$ & & & 82.2 \\
\hline $\mathrm{G} \times \mathrm{E}$ & 143 & $0.561 \mathrm{E}+07$ & 39288.9 & & & 13.1 \\
\hline AMMI1 & 23 & $0.225 \mathrm{E}+07$ & 97949.9 & 3.493 & 0.000 & 43.2 \\
\hline AMMI2 & 21 & $0.125 \mathrm{E}+07$ & 59775.3 & 2.804 & 0.000 & 23.5 \\
\hline AMMI3 & 19 & 744988.0 & 39209.9 & 2.298 & 0.005 & 11.3 \\
\hline AMMI4 & 17 & 501151.1 & 29479.4 & 2.149 & 0.015 & 8.8 \\
\hline Residual $\mathrm{G} \times \mathrm{E}$ & 63 & 864050.0 & 13715.1 & & & 13.2 \\
\hline Total & 167 & & & & & \\
\hline
\end{tabular}

Results of this analysis also showed that the first principal component of interaction (first component of AMMI) accounted for approximately $43 \%$ and second principal component accounted for about $24 \%$ of the GEI sum of squares, and cumulatively both AMMI1 and 2 explained approximately $67 \%$ of the total interaction of GE. Primary evaluations showed that, all estimated principal components are significant at $1 \%$ level. Meanwhile, residual (noise) included about $13 \%$ of GE sum of square. In this study, the best estimated model has obtained via two IPC1 and IPC2 components. Although some authors suggest use of four main components as necessity to estimate the AMMI model (Thillainathan \& Fernandez, 2001); however, review of the literatures suggests that factors such as the type of crop plant, germplasm diversity, and range of environmental conditions are effective on the degree of complexity of the estimated model (Malhotra \& Singh, 1991; Atta \& Shah, 2009; Acikgoz et al., 2009).

In order to observe the pattern of interaction between genotype and environment and interpret the results, biplot polygons were used (Yan \& Kang, 2003). Corresponding to GGE biplot method and through symmetric scoring, biplot of IPC1 against IPC2 was drawn and given in Figure 2. In this biplot, 65 percent of variation explained belongs to GE interaction and genotypes with highest distance to the origin of coordinate have attached together with dash line and made biplot polygon. Among these genotypes, entries such as V6, V11, and V4, which are vertices of the polygon, produced the highest seed yield in this study. Based on the biplot, five rays divided the biplot to the five sections and environments fell in three of them and vertex genotype for this section is V6, indicating high yielding genotype for theses environments is V6. Similarly, environments U2 and H1 fell into section 2 and there is no vertex genotype. Another section including K1, K2, K3, H3, and U3 and vertex genotype for this section is V4.

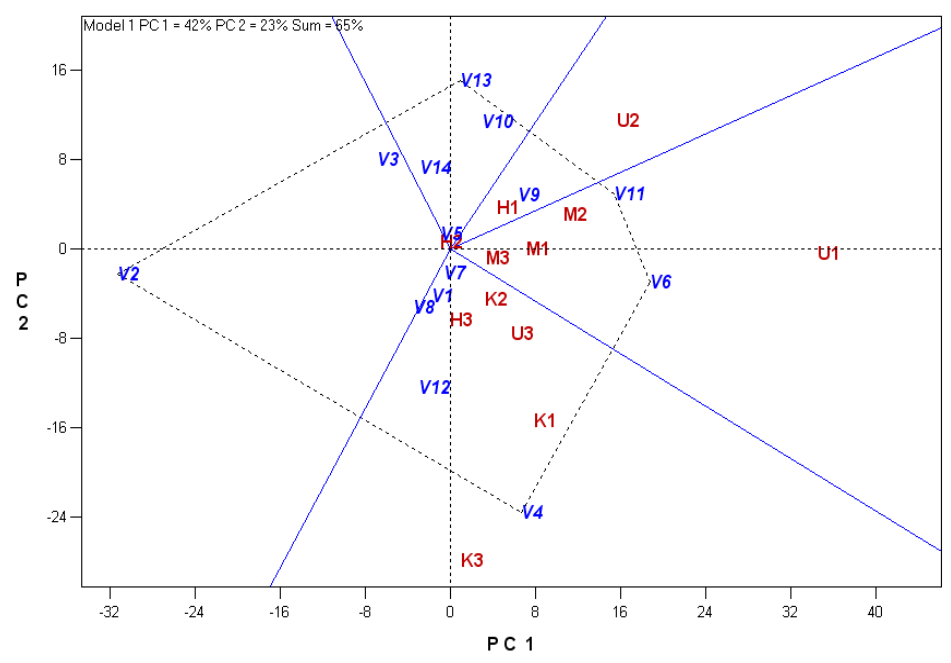

Figure 2. Biplot of first interaction principal components (IPC1) and second interaction principal components (IPC2) scores of 14 chickpea genotypes in 12 environments 
Genotypes, such as V1, V7, V8, and V5 which were close to the origin of coordinate produce average yield at all of experimental environments. Figure 2 implies that there are two main environments for cold highlands of West Iran. First one corresponding with very cold regions, Maragheh and similar environments, where identified with genotype V6, and second one is corresponding with Kurdistan and same environments, where has relatively milder temperature and determined with V4. On the other hand, both AMMI1 and 3 explain more than 53\% of variation, which cannot be ignored. Here, we presented the second biplot, which confirms somewhat the former biplot and show the consistent situation of V6 and V2 (Figure 3). This biplot suggests that genotype V6 with high IPC1and low IPC3 can be considered as more stable genotypes for most of environments.

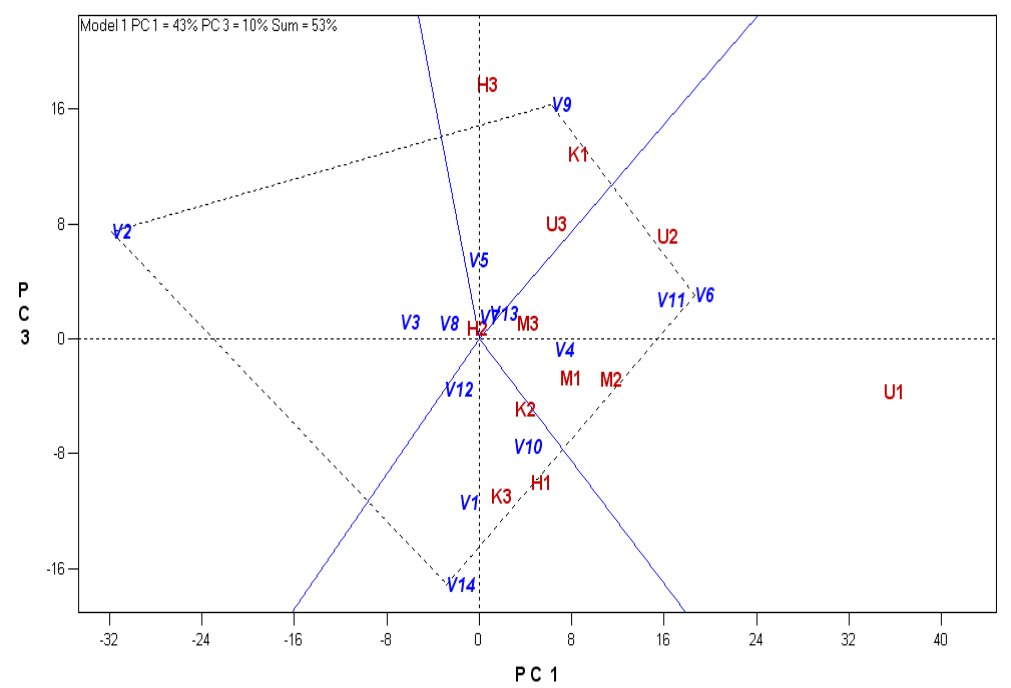

Figure 3. Biplot of first interaction principal components (IPC1) and third interaction principal components (IPC3) scores of 14 chickpea genotypes in 12 environments

The AMMI stability values (ASV) were calculated according to Purchase et al. (2000). The results showed that the first two PCs explained 66.7\% of variance of data set (Table 7). According to the ASV, V5, V7, and V1 are most stable genotypes, respectively. This parameter is comparable with other stability statistics (Purchase et al., 2000).

Table 7. First two principal components and AMMI stability values for 14 chickpea genotypes

\begin{tabular}{llll}
\hline Gen & IPC1 & IPC2 & ASV \\
\hline V1 & 2.47 & 5.75 & 6.63 \\
V2 & 25.19 & -8.17 & 34.72 \\
V3 & 1.814 & -11.03 & 11.29 \\
V4 & 9.48 & 17.44 & 21.56 \\
V5 & -0.31 & -0.82 & 0.92 \\
V6 & -13.66 & 11.79 & 21.75 \\
V7 & 1.674 & 3.88 & 4.48 \\
V8 & 4.288 & 6.06 & 8.35 \\
V9 & -3.687 & -11.43 & 12.45 \\
V10 & -8.37 & -8.47 & 14.05 \\
V11 & -16.37 & 6.39 & 22.84 \\
V12 & 10.44 & 5.78 & 15.14 \\
V13 & -9.74 & -9.39 & 16.08 \\
V14 & -2.28 & -6.30 & 7.01 \\
\% 0 variance & 43.2 & 23.5 & - \\
\hline
\end{tabular}




\subsection{Comparison of Stability Parameters}

Table 8 indicates the ranking orders for 14 chickpea genotypes, according to the different stability parameters. Based on Shukla's stability variance $\left(\sigma_{i}^{2}\right)$, Wricke's ecovalence $\left(W_{i}\right)$, Mean square of GEI (MS(GE)), Kang's Rank sum method (RS), and AMMI stability value (ASV) the most stable genotype was V5. According to mean seed yield of genotypes and Lin and Binns priority index $\left(\mathrm{P}_{\mathrm{i}}\right)$, the superior genotype was $\mathrm{V} 4$.

Spearman's coefficient of rank correlation was employed for each of pair wise comparisons of the ranks of stability parameters (Table 9). The mean of seed yield was correlated to the stability parameters $\mathrm{Pi}(\mathrm{r}=0.96 * *)$, $\mathrm{D}^{2}{ }_{\mathrm{i}}(\mathrm{r}=-0.57 *)$, and Tai's $\alpha_{\mathrm{i}}\left(\mathrm{r}=-0.55^{*}\right)$. Ecovalence $\left(\mathrm{W}_{\mathrm{i}}^{2}\right)$, stability variance $\left(\sigma \mathrm{i}^{2}\right), \mathrm{D}^{2}{ }_{\mathrm{i}}, \lambda \mathrm{i}$ and AMMI stability value (ASV) were highly correlated $(\mathrm{P} \leq 0.01)$. These results showed that one of these parameters could be used as a substitute for the others in GE interaction study of chickpea. Plaisted stability parameter $\left(\theta_{(\mathrm{i})}\right)$ had high negative correlation with stability variance $\left(\sigma_{i}^{2}\right), D_{i}^{2}, \lambda_{i}$ and Purchase's AMMI stability value (ASV). Regression coefficient $\left(b_{i}\right)$ had positive correlation with ASV at $5 \%$ probability level. Correlation between coefficient of variation $(\mathrm{CV}), \mathrm{D}_{\mathrm{i}}{ }_{\mathrm{i}}$ and $\alpha_{\mathrm{i}}$ was significant at 5 and 1 percent probability levels, respectively. $\mathrm{P}_{\mathrm{i}}$ had positive and significant correlation with the procedures of MS(GE) and RS. Desirability index $\left(D^{2} \mathrm{i}\right)$ correlation with Tai's stability parameter $\left(\lambda_{i}\right)$ and ASV was positive and significant $(\mathrm{P} \leq 0.01)$. Meanwhile, rank sum (RS) was correlated with ASV at 5\% probability level. Purchase et al. (2000) found same findings in a wheat study.

Table 8. Ranking orders of mean yield and various stability parameters of 14 chickpea genotypes evaluated across 12 environments in the chickpea growing areas west of Iran

\begin{tabular}{llllllllllllll}
\hline Gen. code & Mean & $\mathrm{W}_{\mathrm{i}}$ & $\theta_{(\mathrm{i})}$ & $\mathrm{b}_{\mathrm{i}}$ & $\mathrm{CV}$ & $\mathrm{P}_{\mathrm{i}}$ & $\mathrm{MS}(\mathrm{GE})$ & $\sigma_{\mathrm{i}}^{2}$ & $\mathrm{D}_{\mathrm{i}}^{2}$ & $\alpha i$ & $\lambda i$ & $\mathrm{RS}$ & $\mathrm{ASV}$ \\
\hline V1 & 9 & 5 & 10 & 6 & 5 & 8 & 2 & 5 & 3 & 4 & 7 & 8 & 3 \\
V2 & 14 & 14 & 1 & 14 & 8 & 14 & 14 & 14 & 8 & 1 & 14 & 14 & 14 \\
V3 & 13 & 3 & 12 & 9 & 2 & 12 & 12 & 3 & 1 & 2 & 1 & 10.5 & 6 \\
V4 & 1 & 13 & 2 & 11 & 9 & 1 & 5 & 13 & 12 & 12 & 13 & 8 & 11 \\
V5 & 8 & 1 & 14 & 8 & 6 & 7 & 1 & 1 & 2 & 10 & 3 & 1 & 1 \\
V6 & 2 & 11 & 4 & 13 & 13 & 2 & 4 & 11 & 14 & 14 & 5 & 5 & 12 \\
V7 & 6 & 4 & 11 & 4 & 4 & 6 & 3 & 4 & 4 & 6 & 6 & 2 & 2 \\
V8 & 10 & 2 & 13 & 10 & 12 & 9 & 7 & 2 & 7 & 11 & 4 & 3 & 5 \\
V9 & 3 & 10 & 5 & 5 & 1 & 3 & 10 & 10 & 10 & 5 & 11.5 & 5 & 7 \\
V10 & 7 & 7 & 8 & 1 & 7 & 10 & 9 & 7 & 9 & 8 & 10 & 8 & 8 \\
V11 & 4 & 12 & 3 & 12 & 14 & 5 & 8 & 12 & 13 & 13 & 9 & 10.5 & 13 \\
V12 & 5 & 8 & 7 & 7 & 3 & 4 & 6 & 8 & 6 & 3 & 11 & 5 & 9 \\
V13 & 12 & 6 & 9 & 3 & 10 & 11 & 11 & 6 & 5 & 7 & 8 & 12 & 10 \\
V14 & 11 & 9 & 6 & 2 & 11 & 13 & 13 & 9 & 11 & 9 & 11.5 & 13 & 4 \\
\hline
\end{tabular}


Table 9. Rank correlation coefficients among mean yield and stability parameters of 14 chickpea genotypes in 12 environments

\begin{tabular}{lllllllllllll}
\hline Parameter & Mean & $\mathrm{W}_{\mathrm{i}}$ & $\theta_{(\mathrm{i})}$ & $\mathrm{b}_{\mathrm{i}}$ & $\mathrm{CV}$ & $\mathrm{P}_{\mathrm{i}}$ & $\mathrm{MS}(\mathrm{GE})$ & $\sigma_{\mathrm{i}}^{2}$ & $\mathrm{D}_{\mathrm{i}}^{2}$ & $\alpha i$ & $\lambda i$ & $\mathrm{RS}$ \\
\hline $\mathrm{W}_{\mathrm{i}}$ & -0.36 & & & & & & & & & & \\
$\theta_{(\mathrm{i})}$ & 0.36 & -1.00 & & & & & & & & & \\
$\mathrm{~b}_{\mathrm{i}}$ & -0.14 & 0.39 & -0.39 & & & & & & & & \\
$\mathrm{CV}$ & -0.06 & 0.31 & -0.31 & 0.34 & & & & & & & & \\
$\mathrm{P}_{\mathrm{i}}$ & $0.96^{* *}$ & -0.25 & 0.25 & -0.25 & 0.02 & & & & & & & \\
$\mathrm{MS}(\mathrm{GE})$ & $0.53^{*}$ & 0.35 & -0.35 & -0.08 & 0.06 & $0.63^{*}$ & & & & & & \\
$\sigma_{\mathrm{i}}{ }^{2}$ & -0.36 & $1.00^{* *}$ & $-1.00^{* *}$ & 0.39 & 0.31 & -0.25 & 0.35 & & & & & \\
$\mathrm{D}_{\mathrm{i}}{ }^{2}$ & $-0.57^{*}$ & $0.79^{* *}$ & $-0.79^{* *}$ & 0.27 & $0.61^{*}$ & -0.40 & 0.18 & $0.79^{* *}$ & & & & \\
$\alpha i$ & $-0.55^{*}$ & 0.12 & -0.12 & 0.20 & $0.75^{* *}$ & -0.47 & -0.36 & 0.12 & 0.61 & & & \\
$\lambda i$ & -0.20 & $0.79^{* *}$ & $-0.79 * *$ & -0.06 & 0.06 & -0.07 & 0.38 & $0.79^{* *}$ & $0.55^{*}$ & -0.13 & & \\
$\mathrm{RS}$ & 0.49 & 0.51 & -0.51 & 0.03 & 0.26 & $0.58^{*}$ & $0.78^{* *}$ & 0.51 & 0.21 & -0.26 & 0.45 & \\
$\mathrm{ASV}$ & -0.19 & $0.82^{* *}$ & $-0.82^{* *}$ & $0.54^{*}$ & 0.42 & -0.14 & 0.41 & $0.82^{* *}$ & $0.63^{*}$ & 0.13 & 0.50 & $0.52^{*}$ \\
\hline
\end{tabular}

Note. ${ }^{*}$ and $* *=$ Significant at 5 and 1 percent probability levels, respectively.

\section{Conclusions}

An ideal variety should be adaptable to a wide range of growing conditions, with above average yield and below average variance across different environments. In the present study, AMMI stability value (ASV) had correlations with a number of other procedures, which imply that AMMI analysis was more efficient than univariate stability parameters and ASV procedure can be useful to rank genotypes. AMMI model, according to two first principal components, has graphical ability to determine chickpea genotypes with high seed yield, stable performance, and broad adaptation. The genotype V5 (FLIP 97-230C) presents high seed yield stability; however, its mean performance was not desirable. Overall, genotypes V4 (FLIP 00-39C) and V6 (FLIP 99-26C) can be recommended to western cold zone farmers of Iran to autumn planting of chickpea. Further studies are warranted to understand why in same environment a genotype is more stable than the others which could be helpful for breeding high yielding stable chickpea cultivars in the region.

\section{References}

Acikgoz, E., Ustun, A., Gul, I., Anlarsal, E., Tekeli, A. S., Nizam, I., \& Yavuz, M. (2009). Genotype × environment interaction and stability analysis for dry matter and seed yield in field pea (Pisum sativum L.). Spanish Journal of Agricultural Research, 7(1), 96-106.

Akter, A., Jamil, H., M., Umma, K. M., Islam, M. R., Hossain, K., \& Mamunur, R. M. (2014). AMMI Biplot Analysis for Stability of Grain Yield in Hybrid Rice (Oryza sativa L.). Journal of Rice Research, 2, 126. http://dx.doi.org/10.4172/jrr.1000126

Atta, B. M., \& Shah, T. M. (2009). Stability analysis of elite chickpea genotypes tested under diverse environments. Australian Journal of Crop Science, 3(5), 249-256.

Becker, H. C., \& Léon, J. (1988). Stability Analysis in Plant Breeding. Plant Breeding, 101, 1-23. http://dx.doi.org/10.1111/j.1439-0523.1988.tb00261.x

Bakhsh, A., Akhtar, L. H., Malik, S. R., Masood, A., Iqbal, Sh. M., \& Qurashi, R. (2011). Grain yield stability in chickpea (Cicer arietinum L.) across environments. Pakistan Journal of Botany, 43(5), 2947-2951.

Crossa, J. (1990). Statistical analyses of multi-location trials. Advances in Agronomy, 44, 55-85. http://dx.doi.org/10.1016/S0065-2113(08)60818-4

Danyali, S. F., Razavi, F., Ebadi-Segherloo, A., Dehghani, H., \& Sabaghpour, S. H. (2012). Yield Stability in Chickpea (Cicer arietinum L.) and Study Relationship among the univariate and multivariate stability Parameters. Research in Plant Biology, 2(3), 46-61.

Eberhart, S. A., \& Russel, W. A. (1966). Stability Parameters for Comparing Varieties. Crop Science, 6, 36-40. 
http://dx.doi.org/10.2135/cropsci1966.0011183X000600010011x

FAOSTAT. (2012). FAO Statistical Yearbook. Food and Agricultural Organization of the United Nations, Rome, Italy. Retrieved from http://faostat.fao.org/site/291/default.aspx

Finlay, K. W., \& Wilkinson, G. M. (1963). The analysis of adaptation in plant breeding programs. Australian Journal of Agricultural Research, 14, 742-754.

Francis, T. R., \& Kannenberg, L. W. (1978). Yield stability studies in short-season maize I .A descriptive method for grouping genotypes. Canadian Journal of Plant Science, 58, 1029-1034.

Gauch, H. G., \& Zobel, R. W. (1988). Predictive and postdictive success of statistical analyses of yield trials. Theoretical and Applied Genetics, 76, 1-10. http://dx.doi.org/10.1007/ BF00288824

Halluer, R., \& Miranda, J. B. (1981). Quantitative genetics in Maize breeding. Iowa State University Press, Ames.

Hanson, W. D. (1970). Genotypic stability. Theoretical and Applied Genetics, 40, 226-231. http://dx.doi.org/10.1007/BF00285245

Hussein, M. A., Bjornstad, Å., Aastveit, A. H., \& Berg, T. (2000). SASG $\times$ ESTAB - A SAS program for computing genotype $\times$ environment stability statistics. Agronomy Journal, 92, 454-459. http://dx.doi.org/10.2134/agronj2000.923454x

Kang, M. S. (1988). A rank-sum method for selecting high-yielding, stable corn genotypes. Cereal Research Communication, 16, 113-115.

Kanouni, H., Taleei, A. R., \& Khalily, M. (2006). Stability analysis of seed yield and one hundred seeds weight in desi type chickpea genotypes under dryland conditions. Seed and Plant, 23, 297-310.

Lin, C. S., \& Binns, M. R. (1988). A superiority measure of cultivar performance for cultivar $\times$ location data. Canadian Journal of Plant Science, 68, 193-198. http://dx.doi.org/10.4141/cjps88 -018

Lin, C. S., Binns, M. R., \& Lefkovitch, P. (1986). Stability analysis: Where do we stand? Crop Science, 26, 894-899. http://dx.doi.org/10.2135/cropsci1986.0011183X002600050012x

Malhotra, R. S., \& Singh, K. B. (1991). Classification of chickpea growing environments to control genotype by environment interaction. Euphytica, 58, 5-12. http://dx.doi.org/10.1007/BF00035334

Pinthus, J. M. (1973). Estimate of genotype value: a proposed method. Euphytica, 22, 121-123. http://dx.doi.org/10.1007/BF00021563

Plaisted, R. L. (1960). A shorter method of evaluating the ability of selection to yield consistently over seasons. American Potato Journal, 37, 166-172.

Plaisted, R. L., \& Peterson, L. C. A. (1959). Technique for evaluating the ability of selections and yield consistency in different locations or seasons. American Potato Journal, 36, 381-385.

Purchase, J. L., Hattingh, H., \& Van Deventer, C. S. (2000). Genotype $\times$ environment interaction of winter wheat (Triticum aestivum L.) in South Africa: II. Stability analysis of yield performance. South African Journal of Plant and Soil, 17, 101-107. http://dx.doi.org/10.1080/02571862.2000.10634878

Raffi, S. A., Newaz, M. A., \& Khan, N. (2004). Stability analysis for pod and seed production in dry bean (Phaseolus vulgaris L.). Asian Journal of Plant Science, 3, 239-242.

SAS institute. (1996). SAS/STAT User's Guide (2nd ed.). SAS institute Inc., Cary, NC.

Shukla, G. K. (1972). Some aspects of partitioning genotype $\times$ environmental components of variability. Heredity, 28, 237-245. http://dx.doi.org/10.1038/hdy.1972.87

Singh, K. B., \& Saxena, M. C. (1999). Chickpeas. In R. Coste (Ed.), The Tropical Agriculturist. Macmillan, London.

Tai, G. C. C. (1971). Genotypic stability analysis and application to potato regional trials. Crop Science, 11, 184-190. http://dx.doi.org/10.2135/cropsci1971. 0011183X001100020006x

Thillainathan, M., \& Fernandez, G. C. J. (2001). SAS applications for Tai's stability analysis and AMMI model in genotype $\times$ environmental interaction (GEI) effects. Journal of Heredity, 92, 367-371. http://dx.doi.org/10.1093/jhered/92.4.367

Wricke, G. (1962). Uber eine Methode zurr Efassung der okologischen Streubretite in Feldversuchen. $Z$ Pflazenzuecht, 47, 92-96. 
Yadav, S. S., Redden, R. J., Chen, W., \& Sharma, B. (2007). Chickpea Breeding and Management (p. 638). Wallingford, Oxon, UK: CAB International.

Yan, W., \& Kang, M. S. (2003). GGE biplot analysis: A graphical tool for breeders, geneticists and agronomist (p. 271). Boca Raton, FL: CRC Press.

Zobel, R. W., Wright, M. J., \& Gauch, H. G. (1988). Statistical analysis of a yield trial. Agronomy Journal, 80, 388-393. http://dx.doi.org/10.2134/agronj2006.0282

\section{Copyrights}

Copyright for this article is retained by the author(s), with first publication rights granted to the journal.

This is an open-access article distributed under the terms and conditions of the Creative Commons Attribution license (http://creativecommons.org/licenses/by/3.0/). 